\title{
MARKET CONDITIONS AND
} RETIREMENT OF PHYSICAL CAPITAL:

EVIDENCE FROM OIL TANKERS

Iain Cockburn

Murray Frank

Working Paper No. 4194

NATIONAL BUREAU OF ECONOMIC RESEARCH 1050 Massachusetts Avenue

Cambridge, MA 02138

October 1992

This paper is part of NBER's research program in Productivity. Any opinions expressed are those of the authors and not those of the National Bureau of Economic Research. 
NBER Working Paper \#4194

October 1992

\title{
MARKET CONDITIONS AND \\ RETIREMENT OF PHYSICAL CAPITAL: \\ EVIDENCE FROM OIL TANKERS
}

\begin{abstract}
The endogeneity of capital retirements is studied for the particular case of oil tankers from 1979--1989. A model is estimated to examine the effect of changes in market conditions on the price and scrappage of tankers. Energy price rises had a major impact on the value of ships and on which ships were scrapped. A simple model is able to account for many features of the market. We use the information implicit in second-hand prices to ease the computational burden for the model that is estimated.

Iain Cockburn

Faculty of Commerce

University of British Columbia

2053 Main Mall

Vancouver, $\mathrm{BC}$

Canada V6T $1 \mathrm{Z2}$

and NBER

Murray Frank

Faculty of Commerce

University of British Columbia

2053 Main Mall

Vancouver, BC

Canada V6T $1 Z 2$
\end{abstract}




\section{Introduction}

\section{$1.1 \quad$ Background}

Depreciation of capital is a fundamental aspect of many dynamic processes in economics. Areas of economics in which depreciation is central include growth theory, business cycle analysis, dynamic oligopoly the ory, national income accounting, productivity measurement, and some aspects of international trade and public finance. Despite the central importance of depreciation, it is common to make convenient simplifying assumptions that may have the effect of distorting the implications of the process. In particular it is common to assume constant geometric depreciation of capital that is independent of market conditions, almost as if this were a technological fact. Depreciation is, however, at least. partly endogenous and many patterns of depreciation are possible. As stressed by Hulten (1990) and Berndt (1991), among others, given the importance of the capital depreciation process there is surprisingly little evidence concerning its actual character.

This paper provides some empirical analysis of one component of depreciation, the important but neglected issue of capital retirement. The particular case examined is the oil tanker industry, which has a number of features that allow us to address some questions of general significance. Firstly, what determines the decision to scrap a piece of physical capital? Are depreciation and retirement of capital determined by engi-

Murray Frank gratefully acknowledges research support from Social Sciences and Humanities Research Council of Canada grant 410-91-0727. Iain Cockburn's work was supported in part by a UBC-HSS grant. We thank J. Brander, S. Das, R. J. Gordon, Z. Griliches, R. Hall, T. Heaver, M. Puterman, and S. Rosenthal for useful comments. Mailing address for both authors: Faculty of Commerce and Business Administration, 2053 Main Mall, University of British Columbia, Vancouver, BC, Canada V6'T 1Z2. 
neering considerations, independent of market conditions? Secondly, did the energy price increases of the 1970s actually affect these decisions? To what extent can the energy price rise be understood as a negative technological shock to this industry?

While the main focus of this study is on the economics of capital retirement, it also makes a methodological point concerning the estimation of dynamic structural models in the presence of a second hand market. A simple partial equilibrium model is estimated, in which the ship owner is modeled as solving a dynamic decision making problem about when to retire a tanker. Estimation of dynamic programming models normally involves certain technical problems. One must keep track both of the present period and also have a consistent treatment of the rest of the program facing the decision maker, see Eckstein and Wolpin (1989), Pakes (1991), and Rust (1992) for useful surveys. Using information from the second hand market for ships substantially reduces the computational and technical difficulties. By making the assumption that used ships are efficiently priced, the analysis is drastically simplified. In essence the estimation of a complex dynamic model reduces to a familiar discrete choice model. This simplification may be of use to others who are interested in studying assets for which efficient second hand markets exist.

\subsection{The case of oil tankers}

Oil tankers play a vital role in the world economy, but quite apart from the industry's intrinsic importance (discussed in the appendix) there a number of features of its institutions and its technology which make it particularly well suited to examining depreciation. Firstly, ships are traded on well-developed and closely watched markets. The institutions of this market make it possible to easily identify and track individual 
pieces of capital - tankers - over time. The market is highly competitive and most transactions are "off shore" and therefore free from distortions induced by, for example, tax policy. Secondly, the industry is fairly turbulent. Prices of used tankers, scrapping, and deliveries of new ships fluctuate substantially over time - there is plenty of "action" in the phenomena we are trying to measure.

The third advantage is the large and direct effects of energy prices on both the demand for tanker services and the costs of supplying these services. There are two particularly important components here. First, oil tankers are used to transport oil: if the demand for oil decreases, then there is less demand for the services of oil tankers. Second, oil is a major input in the operation of a tanker. As a result of the energy price changes, fuel costs rose from about $13 \%$ of total operating costs in 1970 to about $34 \%$ in 1985 , see Stopford (1988, page 108).

The fourth advantage of examining oil tankers is that compared to many other capital goods they are relatively homogenous. Most of the economically significant heterogeneity of tankers is captured by a small number of observable characteristics: size, age, and engine technology. Engine technology is particularly interesting. At the start of our period there were two distinct engine technologies in wide use, steam turbines and diesels. Steam turbines had about a $30 \%$ thermal efficiency while the older diesels had a thermal efficiency of about $40 \%$. By the end of the period under consideration the thermal efficiency of diesels had risen to about $53 \%$. Since diesels consume less energy, they can also travel further without refueling. If energy price shocks matter, then we should expect the energy price increases to have had a negative impact on the value of steam powered vessels relative to diesels. The existence of these two technologies makes for a particularly clear case to study. As discussed in 
the appendix, there is considerable institutional evidence of adjustments made in reaction to the energy price increases.

The results of this study show that retirements are quite sensitive to market conditions. Which ships get scrapped, and at what age they get scrapped, seems to be endogenously determined by the relationship between the value of the ships in use and their scrap value. The energy price increases had a substantial impact on these decisions. This implies that the popular assumption of constant geometric depreciation is not justified in this case. ${ }^{1}$ Interestingly if one were to ignore retirement of capital, and focus simply on ships being sold for further trading, one might have been tempted to conclude that the constant geometric depreciation assumption is a reasonable approximation.

Section 2 discusses the relationship between depreciation and the retirement of capital. The model that we estimate is discussed in section 3. The model is a simple partial equilibrium dynamic programming problem. The data set is described in section 4. The nature of the data is discussed, and descriptive statistics are presented and discussed. Our empirical results are presented in section 5 . Conclusions are contained in section 6. An institutional appendix discusses the oil tanker industry in more detail.

\section{Depreciation and Retirement of Capital}

Depreciation of an existing stock of capital can be decomposed into two effects: deterioration or degradation of the level of capital services pro-

\footnotetext{
${ }^{1}$ Hall $(1988,1989)$ has studied the invariance properties of the Solow productivity residual. One implication of our findings is that such invariance does not hold in the tanker market.
} 
vided by assets in use, and withdrawal of assets from use. These effects are commonly summarized by a depreciation schedule which describes the evolution of the level of services provided by an asset over its lifetime. This depreciation schedule is almost invariably assumed to be exogenously determined by engineering considerations, and to be unchanging over time. Similarly, an unchanging distribution of retirement ages is usually assumed. The retirement distribution truncates the depreciation schedule.

In contrast to common practice, there are good reasons for supposing that depreciation schedules are endogenously determined by market conditions and the optimizing behavior of asset owners. One potentially important issue is that increased utilization may cause machinery to wear out faster, making depreciation a function of output rather than of time. Another is that asset owners have the option to vary the intensity and frequency of maintenance activities. In this study the focus is on retirements, and as argued by Feldstein and Rothschild (1974), the contention is that it may be unrealistic to assume that retirements are determined exogenously when asset owners have the option of scrapping or otherwise disposing of assets in response to changes in relative prices, shocks to demand or other market conditions.

Most of the evidence gathered on depreciation has addressed the controversial issue of the shape of depreciation schedules. Various patterns of depreciation have been proposed, ranging from "geometric", in which productive capacity decays at a constant rate $\delta$, to "one-hoss shay" in which an asset continues to provide the same level of services until it falls apart. Studies of vintage asset prices such as Hulten and Wykoff (1981) typically show convex age-price profiles, which seem to be remarkably stable over time. Hulten, Robertson, and Wykoff (1989) found that even 
such a large shock as the energy price increase of 1973 appeared not to have caused age-price profiles to steepen significantly. This evidence has been interpreted by Jorgenson (1989) and others, as supporting the popular hypothesis of constant geometric depreciation rates. ${ }^{2}$

There have been very few published studies of capital retirement. Longitudinal data on individual pieces of capital are rarely collected, and very little is known about distributions of service lives for productive assets, let alone about the stability of these distributions over time. Current practice in statistical agencies, and in much academic research, relies largely upon two venerable studies, the Winfrey (1935) distributions on retirements and the US Treasury's Bullelin $F(1942)$ on asset lives. ${ }^{3}$ The weakness of these data and the assumption that retirements are independent of market conditions have been identified by Hulten (1990) as one of the most serious problems in capital measurement.

In this study scrapping decisions are modeled as being determined by optimizing decisions taken in reaction to the primitives of the problem, such as factor prices and demand for the final product. If the economic variables have insignificant coefficients then one can reject their importance. If the economic variables turn out to be significant, and have the expected signs, then we take this as evidence in support of the idea that retirements are driven by market conditions as well as engineering considerations. This would imply that at least some aspects of the overall depreciation of the capital stock are endogenous.

The size of the effect of accelerated or decelerated retirements on the overall depreciation rate of the capital stock of a given industry or econ-

\footnotetext{
${ }^{2}$ Note however that in a somewhat different context Pakes and Griliches (1984) find evidence of a concave depreciation schedule that is time-dependent. Ohta and Griliches (1986) also show that the inferences to be drawn concerning the effect of energy price increases may be sensitive to the approach taken to testing.

${ }^{3}$ Some additional data was collected by the Department of Commerce in the 1970s.
} 
omy, depends upon factors such as the size of total retirements relative to the outstanding stock. For some industries the effect may be small enough to safely ignore in empirical work. In others, such as oil tankers, we believe the standard assumption of a constant exogenous depreciation schedule is untenable. Only further study of capital retirements can show how many industries fall into each category.

\section{The Model}

In order to have a basis for parametric estimation one needs some sort of model of the phenomenon being studied. The model specifies functional forms and imposes certain restrictions. In the present case there are two aspects to our model that need emphasis. First, we currently lack suitable data to construct a dynamic general equilibrium model of the shipping market. ${ }^{4}$ Our analysis is partial equilibrium in that we take a number of market prices to be exogenous. Second, we assume that the market is perfectly competitive.

The importance of perfect competition for our analysis comes from standard theory. In perfectly competitive markets there is often an equivalence between the "benevolent social planner's decisions" and the market equilibrium, see Stokey and Lucas (1989, chapter 15) for a more precise statement. If this applies then the market solves a single dynamic optimization problem. In this case we think of each ship as an individual realization from the same process. One can talk of either the ship owner's decision, or equivalently, the social planner's decision. This allows us to

\footnotetext{
${ }^{4}$ Such a model would include the determinants of ship building, ship lay up, and ship scrapping. Ideally it might also include a multidimensional set of choices for the use of the ship in each period. For example it might include crewing, maintenance, and routing decisions.
} 
treat different ships as if they are simply realizations from the same underlying process.

The market for used assets is assumed to be perfectly efficient and there are no asymmetries of information amongst the market participants. With second hand ships traded in a perfectly efficient market, the market price of the ship is just the discounted present value of the future net cash flows that the ship is expected to generate if it is used optimally in all future periods.

At time $t=0$ there are $j=1, \ldots, J$ ships afloat. Each period from $t=$ 0 onwards, the owner of the ship is obliged to make a decision concerning the disposition of the ship. There are three feasible choices. The ship can be sold for scrap $(i=0)$. It can be sold for further trading $(i=1)$. Or, the owner can "sell" the ship to himself for further trading $(i=2) .^{5}$ The owner will sell the ship for scrap if that is more valuable than the returns from the alternatives.

Given our conditions on the efficiency of the second hand market, the ship owner who is not scrapping his ship will be exactly indifferent between selling the tanker for further trading, or "selling" the ship to himself for further trading, and so we subsume $(i=2)$ into $(i=1)$. This important simplification allows us to evaluate the expected value of the program for ships that are not scrapped, by examining the market prices of ships sold for further trading. A decision to scrap a tanker is obviously not reversible. Our set up of the problem implies that the decision to "sell" a ship, whether on the market or to oneself, is also taken to be a terminating action.

As in much asset pricing theory, one might ask: why should we ever

\footnotetext{
${ }^{5}$ We do not have data concerning when particular ships were in lay up. We expect that this must effect less efficient and older ships more than newer energy efficient ships. When we refer to a ship as being operated this implicitly includes lay up.
} 
observe asset sales if the market is truly efficient? In the financial asset pricing literature a common answer is to assert that a liquidity need strikes the existing owner of the asset. For exarnple this might be some unrelated business opportunity requiring cash to exploit. The important feature, however one chooses to phrase this assumption, is that the decision to sell the asset should not in itself be informative as to the state of the asset. From discussions with people who have institutional knowledge of this market, we believe that this is not a bad approximation for the example of oil tankers.

The set of state variables, $X_{j t}$, that faces a ship owner in any period is fairly simple: the ship exists (or not), the ship is of a particular age, the ship has a set of physical characteristics, the current energy price, the current price of a used ship sold for scrap, the price of a used ship sold for further trading. We also assume that there are state variables seen by the market participants that cannot be observed by the econometrician. This assumption generates an error term in the manner that is conventional in discrete choice analysis, see McFadden (1981). In the empirical work we examine different specifications of the set of state variables. For example, in some runs we deleted the energy price.

The dynamics of the problem are particularly simple. A ship is assumed to exist. If a ship does not exist then obviously there is no decision and no reward. Each period the ship ages by exactly one period. The length of a time period is a quarter of a year in the empirical work. The physical characteristics of the ship, the market price of energy, the prices of ships sold for further trading, and the prices of ships sold for scrap, are assumed to be exogenous.

The one period return at time $t$, to the owner of ship $j$, from choice $i$, is $U_{j t}^{i}$ which is unobserved by the econometrician, but assumed to be made 
up of a deterministic component which is a function of some (potentially choice-specific) observed exogenous variables plus an error term

$$
U^{i}\left(X_{j t}^{i}, \beta^{i}\right)=R\left(X_{j t}^{i}, \beta^{i}\right)+\epsilon_{j t}^{i}
$$

The ship owner's problem is to formulate a decision rule for choosing over alternatives $i$ in each period, in a way that maximizes the discounted present value of utility over an infinite horizon. The familiar recursive formulation of this problem is given by Bellman's equation

$$
V\left(X_{j t}, e_{j t}\right)=\operatorname{Max}_{i}\left\{R_{j t}^{i}\left(X_{t}^{i}, \beta^{i}\right)+\epsilon_{j t}^{i}+\delta E V\left(X_{j t}, \epsilon_{j t}, i\right)\right\}
$$

This functional equation defines the ship owner's value function (maximum expected discounted utility obtainable in period $t$ ) in terms of the discount rate $\delta$, a vector of parameters $\beta=\left(\beta^{0}, \beta^{1}\right)$, state variables $X_{j t}=\left(X_{j t}^{0}, X_{j t}^{1}\right)$, error terms $\epsilon_{j t}=\left(\epsilon_{j t}^{0}, \epsilon_{j t}^{1}\right)$, and $E V$, the expected value of the rest of the program conditional on the state variables and choice $i$. In general both the exogenous variables and the functional form of $R$ can be expected to differ across actions.

To obtain a statistical model we follow the literature on logit and dynamic discrete choice. Rust (1988) showed that certain assumptions allow for dynamic versions of logit analysis. In particular, $\epsilon_{j t}^{i}$ follows a multivariate extreme value distribution. This assumption is a conventional distributional assumption used in static logit models, see McFadden (1981).

Given these assumptions, the probability of choosing $i$ is given by

$$
P\left(i \mid X_{t}, \beta\right)=\frac{e^{R^{i}+\delta E V\left(X_{1}, i\right)}}{e^{R^{0}+\delta E V\left(X_{1}, 0\right)}+e^{R^{1}+\delta E V\left(X_{i}, 1\right)}}
$$

For the ship owner's problem, this expression simplifies considerably. Suppose he chooses to scrap $(i=0)$ the ship in period $t$. Then an 
immediate lump sum is received in period $t$ and zero is received in all future periods. The probability of scrapping is thus

$$
P\left(0 \mid X_{j t}, \beta\right)=\frac{e^{R^{0}}}{e^{R_{j t}^{1}+\delta E V\left(X_{j t}, 1\right)}+e^{R_{j 1}^{0}}}
$$

We now have a version of the model derived by Rust (1988). The issue is then how to solve the model. Rust invokes an assumption of conditional independence, and notes that the expected value of the rest of the program satisfies a particular contraction mapping. He then combines this contraction mapping with a maximum likelihood algorithm to estimate the parameters of the model. The result is an interesting but non-trivial problem in numerical methods. We do not follow this aspect of Rust's approach.

Instead we exploit the assumption that the second hand market is efficient. In an efficient market, the value function conditional on choice $i=1$ will just be the market price of the tanker, $P_{j t}=R_{j t}^{1}+\delta E V\left(X_{j t}, 1\right)$. If the ship is operated this period, the expected return to the owner is this period's charter rate, plus the expected discounted value of the rest of the program conditional upon deciding to operate this period. We assume that competitive bidding by informed participants in the market makes the price of the ship equal to this amount. Now $P\left(0 \mid X_{j t}, \beta\right)=$ $e^{R_{j t}^{0}} /\left(e^{P_{t}}+e^{R_{j t}^{0}}\right)$ and substituting for $R_{j t}^{0}$ from above we get

$$
P\left(0 \mid X_{t}, \beta\right)=\frac{e^{X_{j t}^{0} \beta^{0}}}{e^{P_{j t}}+e^{X_{j t}^{0} \beta^{0}}}
$$

which is just a simple discrete choice logit model, using $P$ and $X$ as explanatory variables.

How do we implement equation 5? In particular, from where do we get $P_{j t}$, the current market price of the ship? We use a two-stage method somewhat analogous to that used to handle endogenous explanatory vari- 
ables in discrete choice models. Using a different data set which is a sample of transactions in which ships were sold for further trading (in which almost none of the subsequently scrapped ships appear) we estimate an auxiliary hedonic price equation by regressing price per dwt on to the observed characteristics of ships sold for further trading and variables capturing market conditions. We then use the estimated parameters of this equation together with data the characteristics of the ships in our scrapping data set to impute the market price the subsequently scrapped ship could have been sold for in the second hand market in each period.

That is to say, using our data set on transactions for further trading $\widetilde{P}_{k t}$ and $\widetilde{X}_{k t}$, we estimate $\widetilde{P}_{k t}=g\left(\widetilde{X}_{k t}, \gamma, v_{k t}\right)$ where $\gamma$ is a vector of parameters and $v_{k t}$ is an i.i.d. normal error. Given the estimated parameters $\hat{\gamma}$, we take the characteristics of the ships in our data set on scrapping transactions, $X_{j t}^{1}$, substitute them into the equation we estimated, and obtain $\hat{P}_{j t}=g\left(X_{j t}^{1}, \hat{\gamma}\right) .^{6}$

To complete our model for ship scrapping we need to specify the specific functional forms of $R^{0}(X, \beta)$ and the auxiliary price equation which is equivalent to $R^{1}$. We postulate that these are simple semi-log functions of $A G E$ (number of periods since the ship was built), $D W T$ ("deadweight tons", a measure of the size of the ship), $D W T^{2}$, and STEAM (a dummy variable taking a value of 1 if the engine is a steam engine, and taking a value of 0 if it is a diesel type engine). There are a number of variables

\footnotetext{
${ }^{6}$ Our procedure means, of course, that $\hat{P}_{j t}$ is estimated rather than observed. This introduces a further random effect into the equation. Since this random effect is orthogonal to the other explanatory variables by construction, and to keep the analysis as simple as possible we choose not to make a further distributional assumption and then integrate it out. Rather, we simply subsume this additional source of error into $\epsilon_{j t}^{i}$ discussed above, and interpret the logit coefficients as known up to a scale factor which is the average standard deviation of the heteroscedastic error terms, $\bar{\sigma}_{i}$ rather than the normal $\vec{\sigma}$. This means that the estimated coefficients are slightly downward-biased compared to their "true" values, see Yatchew and Griliches (1985), Ruud (1982).
} 
that affect all tankers in much the same way, for example energy prices, interest rates, current demand conditions, etc. These effects are controlled for by using quarterly time dummy variables, and we also report some regressions which employ energy prices directly.

\section{The Data Set}

\subsection{Sources}

The world shipping market is unusually closely monitored. There are several very useful sources of detailed information about most of the ships in the world. We have drawn heavily on four main primary sources: Drewry's Shipping Statistics and Economics, ISL Shipping Statistics, Lloyd's List, and Lloyd's Register. The first two of these publications are monthly commercial publications that have existed for many years, and are our primary source of data on transactions prices for ship sales. Ships are identified in these publications by name, and where data on important variables was not reported, or appeared to be in error, the ship was looked up in Lloyd's Register. Though names change with ownership, Lloyd's assigns each a unique ID number, and in some cases we were able to track the same ship through as many as seven transactions before it was finally scrapped. Unfortunately, as is the case with national statistical agencies, every few years these publications alter their methods of data presentation somewhat. This makes is harder to construct the long-term panel of data that would be desired and as a result we have focused largely on data for the years 1979-1989. Ships below about 10,000 DWT in size are not included in these sources, since they are not deemed to be "significant". 


\subsection{Descriptive Statistics}

Descriptive statistics for the variables of interest in the current study are presented in Tables I and II. Table I summarizes transactions in which ships were sold for scrap. We have a total of 853 complete observations on sales for scrap for the period 1979-1989. (An additional 96 transactions for which prices were not reported are included in the logit scrapping model below.) The annual count of scrapping transactions ranges as high as 168 ships in 1985, and as low as 14 ships in 1989. During the years 1982 through 1985 there were a rather large number of ships scrapped. The ships being scrapped in those years also tended to be fairly large relative to the other years that we observe. The average age of a scrapped ship was just over 18 year for the period as a whole. The age distribution of ships sold for scrap does not appear to be symmetric about the mean. Ships of less than 6 years are not often scrapped. Most of the ships that we observed being sold for scrap are between 6 years and 26 years of age. The price per ldt of a ship sold for scrap seems to be independent of the age of the ship. It also seems to be independent of whether the ship is steam or diesel powered.

Table II presents summary statistics for the 1786 transactions we observed in which ships were sold for further trading. In this case the annual count ranges from a low of 75 in 1983 to a high of 271 in 1989. The average age of a ship sold for further trading remained roughly constant through our time period at about 11.4 years.

The average age of scrapped ships rose noticeably from 1985 to 1989. Since 1985 the price per tonne of ship sold for scrap has also been rising. As is the case for ships sold for scrap, the price per tonne of a ship sold for further trading rose substantially from 1985 to 1989.

In the early 1980 s a high proportion (over $75 \%$ in some years) of the 
scrap sales reported in our sources were steam vessels. This proportion fell over the course of the 1980 s. In the second-hand market, on average $24 \%$ of the vessels sold for further trading between 1979 and 1989 were steam powered tankers. Again, this proportion fell over the sample period. This reflects the fact that, as discussed above and in greater detail in the appendix, the steam vessels were less energy efficient. Accordingly they were tending to be phased out. By the end of the sample period, there were simply fewer of them left.

\section{$5 \quad$ Empirical Results}

We begin with estimation of the parameters of the auxiliary price equation discussed above. Table III presents results from estimating conventional hedonic price equations for oil tankers using data on 1786 transactions in the market for further trading between 1979 and 1989. In these regressions the dependent variable is calculated from the price reported by Drewry's for transactions in which tankers were "sold for further trading." The log of price per $d w t$ is regressed using OLS on variables which capture some important characteristics of each tanker: age, engine type, and size. The use of a semi-log functional form is somewhat arbitrary. It does fit the data well, and is widely used in other studies. A quadratic term in size (DWT) is included to capture potential nonlinearities in the relation between size and price per dwt. (The quadratic term in size has the benefit of allowing a degree of flexibility in approximating the "true" underlying functional form. Higher order terms in size were statistically insignificant, and are not reported here.) Following the example of Hulten and Wykoff (1981) we also experimented with ML estimation of a Box-Cox model, in which estimation of additional parameters allows the age-price profile to be convex, linear, or concave. The results obtained 
did not reject the convexity imposed by the semi-log functional form.

Equation 1a in Table 111 fits the data reasonably well. The $R^{2}$ of 0.61 is fairly high for a micro-level data set covering a 10-year period. All the estimated coefficients are significant, and have the expected signs. Even such a simple model seems able to account for much of the variation in transaction prices in our sample quite well. The coefficient on AGE has a very simple interpretation. Controlling for ship size and engine type, the coefficient on AGE gives a geometric depreciation rate of $2.4 \%$ per quarter. The relationship between size and price per dwt is significantly nonlinear. The coefficients imply a U-shaped relationship, downward sloping over most of the range of ship sizes in the sample, with price per $\mathrm{dwt}$ reaching a minimum at about $300,000 \mathrm{dwt}$. This may reflect economies of scale in construction of tankers, as well as the fact that larger tankers were less cost-efficient on some major routes (Gulf to Rotterdam) during the period when the Suez canal was open. Consistent with our earlier discussion we find that there is a lower price for a steam powered tanker.

Equation $1 \mathrm{~b}$ differs from $1 \mathrm{a}$ by the inclusion of quarterly dummy variables. ${ }^{7}$ These dummies control for unmeasured variation in conditions that affect the tanker market as a whole rather than just an individual ship. These may include changes in the demand for tanker services (as reflected by spot charter rates), changes in various input costs, changes in the size of the fleet due to deliveries of new builds, changes to the world's order book for new ships, and political instability in various parts of the world. While some of these factors are observable, others are not, in particular expectations of future demand and supply conditions. In principle

\footnotetext{
${ }^{7}$ In principle there is enough data to use monthly dummies. We do not do this since it seems to offer little in terms of interpretation (we are not studying political-economy aspects). It also does not add much explanatory power in a statistical sense.
} 
we could collect data on some of the observable variables and include them in the regression. However, it is unclear how to interpret the coefficients in this reduced form context, and there are also problems with the extent to which the observable effects may be confounded with unobservables. Since our concern here is primarily to improve the fit of a reduced form equation, rather than in structural determinants of the price of ships sold for further trading, we prefer simply to use time dummies. These are an economical way to control for both observable and unobservable aggregate effects. Introduction of these 44 quarterly dummies improves the explanatory power of the regression substantially. ${ }^{8}$ Note that both the $R^{2}$ and the adjusted $R^{2}$ rise by roughly the same degree. The estimated coefficients on the age and size variables are essentially unchanged. When we tried running only the dummy variables as explanatory variable, an $\mathrm{R}^{2}$ of only 0.32 was obtained. Accordingly it seems that while market conditions are important, the characteristics of the individual tankers are also a very significant determinant of their market price.

In Equations $1 \mathrm{a}$ and $\mathrm{lb}$ we found that the engine type mattered to the ship price. It is natural to wonder whether there are significant interaction effects between engine type and other characteristics of the ship, and in Equations $2 a, 2 b$, and $2 c$ the dummy variable for steam powered engine is interacted with the other variables, effectively allowing us to estimate a separate price equation for steam-powered tankers. These interaction effects are highly significant. Steam-powered tankers have markedly different age-price and size-price profiles than do diesel powered ships. In Equation $2 \mathrm{a}$ the estimated depreciation rate for steam-powered ships is close to zero, and there is little effect of size upon the price per dwt. Controlling for unobserved market-wide effects with the time dummies

\footnotetext{
${ }^{B}$ Estimated coefficients on the time dummies are not reported here. They can be interpreted as the hedonic price index for oil tankers over this period.
} 
alters the coefficients somewhat. In Equation $2 \mathrm{~b}$ the depreciation rate for steam-powered tankers is estimated as $1 \%$ per quarter, and a small effect of size upon price per dwt can be seen. In Equation 2c the STEAM dumny is interacted with the time dummies to allow further flexibility, but this has essentially no effect upon the estimated coefficients.

In Table IV we substitute a direct measure of energy cost (the quarterly mean price of marine bunker fuel) for the quarterly dummy variables. Equations $1 \mathrm{~b}$ and $2 \mathrm{~b}$ are repeated from Table III to allow easy comparison. No significant change in the coefficients of interest were obtained. The estimated coefficient on the energy price is negative and significant, as might be expected. Higher energy prices both increase operating costs and decrease the demand for tanker services, making ships less valuable. ${ }^{9}$

Table $\mathrm{V}$ presents results from estimating similar price equations for tankers sold for scrap. The quality of the data on the prices paid in these transactions is rather poor. The original sources often report nothing more than "VLCC Tankermeister von Vancouver, 225,000 ldt sold to Taiwanese breakers, for an estimated price of $\$ 14 \mathrm{~m}$ ". Furthermore there is little reason to believe that the characteristics of individual tankers have much effect upon their scrap value per tonne of steel. Larger tankers may be marginally easier to cut apart, and the scrap value of different power plants is quite different, but these are second order effects on scrap value per ldt. This is reflected in the regression results. Equations 3a and 4a have $R^{2}$ 's of almost zero, while the time dummies introduced in Equations $3 \mathrm{~b}, 4 \mathrm{~b}$, and $4 \mathrm{c}$ account for $60 \%$ or more of the variation in prices per ldt. Scrap prices seem to be determined almost entirely by

\footnotetext{
${ }^{9}$ Since the energy cost variable is measured quarterly, i.e. at the same frequency as the time dummies and is the same for all ships, one cannot include both sets of variables in the equation at the same time.
} 
market-wide effects such as demand for scrap steel and the aggregate tonnage of ships sold for scrap.

Table VI presents our main results, in which the scrapping of ships is modeled according to the structural model laid out in the previous section. The data set used here is constructed by taking the scrapping decisions observed in the primary sources between 1979 and 1989, and "counting backwards" to 1979 to generate a partial "history" for each ship. ${ }^{10}$ There are 949 ships; observed on average for 20.67 quarters giving a total of 19,946 observations. Some of the characteristics of each ship remain constant over time, such as size and engine type. These are simply duplicated each period for each ship. Two variables do vary over time. The first is the age of each ship, which by definition increases by one quarter every quarter. The other is the estimated price the ship would sell for on the second hand market in each quarter, which we calculate by substituting its characteristics into the reduced form price equations. The estimated price variable imputed from Equation Ib is labelled P-HAT1 in the tables and the estimated price imputed from Equation $2 \mathrm{~b}$ is labelled P-HAT2. ${ }^{11}$ Equation 5a presents estimates of a simple logit estimation of scrapping, without the imputed price variable. The dependent variable is zero for each observation on a given ship, until the quarter in which we observe scrapping when it is set equal to one. The exogenous variables are defined as above. The estimated coefficients have the expected signs: older ships and steam-powered ships are more likely to be scrapped, and

\footnotetext{
${ }^{10}$ Note that this creates a potential selection bias. By construction towards the end of the sample the bjas will be towards younger than average scrapping. For our data this does not appear to be a major problem: Table I shows that the average age of scrapped ships actually rose towards the end of our sample period.

${ }^{11}$ We thus have a discrete approximation to a hazard model with time varying covariates. Not surprisingly, given the ligh frequency of the data, the approximation is quite good. Results from estimating a Cox Proportional Hazards model using the same data and specifications are essentially identical to those from the logit model (but are obtained at a much higher computational cost) and are not presented here.
} 
the relationship between size and the probability of scrapping follows an inverted- $U$, increasing up to about $300,000 \mathrm{dwt}$ and then falling.

Introducing the imputed price as an explanatory variable has a dramatic effect. (Equations 5b, 5c, and 5d.) The coefficients on AGE, STEAM, and the size variables fall by a factor of about 4 and lose much of their significance. The P-HAT variables, which measure the opportunity cost of scrapping the ship have a strongly significant negative effect. The more valuable the ship is in use, the less likely it is to be scrapped. A very substantial improvement in the fit of the model is observed. The P-HAT variables incorporate the impact of changes in energy prices and other macroeconomic effects which affect the value of the ship in use. As energy prices increase, a ship becomes less valuable (as in Equation 1c or 2d) and, other things equal, its market value falls and it is more likely to be scrapped.

\section{Conclusions}

There are several conclusions to be drawn. First and foremost, it seems clear that retirements of ships do depend on market conditions. Accordingly, an assumption of a constant exogenous rate of economic depreciation is not supported by the data. The depreciation as reflected in the market price, depends on the use to which the ship is going to be put. Ships that are being sold for further trading exhibit a roughly convex price-age profile after adjusting for various economic factors. This is not true of ships being sold for scrap. Ships being sold for scrap sell at roughly the same price independent of the age of the vessel.

There has been some debate over the impact of energy price changes on capital. For tankers the changes in energy prices made a major difference. This shows up in several ways. As discussed particularly in 
the appendix, there is institutional evidence of considerable technological change induced by the increased relative price of energy in the 1970s. The effect of energy price changes is also apparent in the large differences observed in the prices of steam tankers and diesel tankers. Steam tankers are less energy efficient than are diesel tankers. The steam tankers traded at prices that behave similarly to the prices of ships that are being sold for scrap. Steam tankers were also more likely to be scrapped. Over the sample period that we examined, the steam tankers make up a decreasing proportion of the population. Unlike steam tankers, diesel tankers show a more conventional depreciation pattern.

Estimation of dynamic programming models has commonly been computationally difficult. In our context we were able to avoid the computational burden by using the information that is implicit in the second-hand market. Unlike many previously studies, for our problem there is an active second-hand market. By exploiting the information contained in these prices we were able to reduce the computational burden. This approach may be useful for others studying assets for which second-hand market prices are available.

Relatively simple specifications are able to account for a good deal of the price variation in tankers. The decision to scrap a tanker depends crucially on the price that the same tanker could fetch in use. This is reflected in the importance of the imputed price in explaining the scrapping decision. While the empirical evidence of the importance of opportunity costs should not surprise economists, it does pose a problem for the manner that capital depreciation is often modeled. At least for this type of capital good, retirements are not driven simply by engineering considerations. Accordingly one should not expect an invariance of these decisions when economic conditions change. 
There are several directions for further work that we hope to pursue. We would very much like to obtain evidence on two matters, new ship delivery and lay up of existing ships. Until data on new ships is obtained we cannot produce a general equilibrium model of the market. Data on lay up decisions could enrich our understanding particularly of the imputed options ${ }^{12}$ in ship prices.

${ }^{12}$ For example see Pindyck (1991). 


\section{Appendix: Some Institutional Background Information}

\section{The Tanker Industry}

Ships are a vital part of the world economy, annually moving large volumes of many economic products all round the globe. They range widely in size and design. In this paper we consider only oil tankers. In January 1991 the world's merchant fleet totaled $642,650,600$ gross tonnes (this includes only ships of size at least $300 \mathrm{gt}$ ). The tonnage of oil tankers consisted of $256,067,100 \mathrm{gt}$. In other words roughly $40 \%$ of the world's merchant fleet consisted of oil tankers.

The importance of oil is familiar. The associated importance of oil tankers is due to the equally familiar point that much oil is produced in different locations than it is used for production. ${ }^{13}$ Ships are used as the major source of transportation (along with pipelines) to move oil from where is found to where it is needed.

Several features of this market are noteworthy. Ships are large, durable pieces of capital. Once built, they last for many years. The gap between the date on which a new ship is ordered and the date on which it is delivered can easily be 2 years. At any moment some ships are in lay up. These ships can be brought into service more rapidly than can new builds. The volume of tonnage in lay up varies. For example in November 1990 there were $2,353,600 \mathrm{gt}$ of oil tankers laid up. That is to say, just under $1 \%$ of the world's merchant fleet of oil tankers were laid up. Often the percentage in lay up is higher still.

${ }^{13}$ The 1990 world oil production in millions of tomnes: North America 500.7, Caribbean 288.1, Other Latin America 79.6, Western Europe 198.8, Eastern Europe and USSR 585.3, Africa 317.5, Middle East 825.3, Far East 313.2, other and errors 41.9, World total 3150.4. Source: ISL Shipping Statistics, Jan/Feb 1991. 
There are not only many ships in the world, there are also large numbers of ship owners. An assumption that this is a highly competitive market is likely to be a better approximation than many other markets economists have studied closely. Similarly there are many different companies and countries that build ships. There is some heterogeneity in the quality of these new builds. This heterogeneity is well known and the ships are priced accordingly.

Demand for shipping services is subject both to long term trends, as well as day to day fluctuations. From about 1970 to 1983 there was a major surge in the volume of crude oil transported by ship. Since 1983 the volume seems to have returned to the underlying trend that had been prevailing since the early 1960 s. Long term market trends can be adjusted to by building new ships and scrapping old ships.

Responding to the shorter term fluctuations in demand for shipping services are quite a different matter. On a month to month basis the supply of ships is almost fixed, so even small fluctuations in demand can, and do, produce huge freight rate price reactions. Many commentators on the industry have pointed to the limited ability to forecast future freight rates as a real problem for the industry.

The international nature of this industry mean that tax considerations are less prominent here than in many industries. This is because countries have competed to get ships registered in their country. These so called flags of convenience offer several advantages. The advantages for the shipping firms include low taxes, avoidance of safety standards, and generally little governmental pressure. The ability to use lower cost labor is of particular importance as it can reduce to cost of crewing by as much as $45 \%$ (Branch (1988), page 18). The main flags of convenience have been Liberia and Panama, as well as Cyprus, Singapore, and Oman. 


\section{Tankers and Energy}

Once a ship has been built, it requires management to find it employment, a crew to run it, energy to power it, and periodic maintenance. Ships do not last forever. Eventually they either sink, or get scrapped. Between 1970 and 1985 energy went from being a relatively small concern, to being a first order issue, due to the energy price increases. Bunker fuel rose from $\$ 20$ a tonne to $\$ 180$ a tonne where it stayed for several years. At that level oil accounted for as much as $50 \%$ of the operating budget for most vessels. Even at $\$ 80$ a tonne, oil costs typically equaled manning costs. As a result many adjustments were made in order to economize on the use of fuel.

The single most important adjustment concerns the speed at which existing ships run. The horsepower of the main engine on a ship sets an upper limit on how fast a ship can travel, however ships can be run slower - "slow steaming". Over plausible ranges of speeds, a $10 \%$ increase in speed normally requires a $30 \%$ increase in fuel consumption. Hence slow steaming can economize on fuel to a considerable degree. Whether it is economical to do so depends upon both the price of energy and the demand for tanker services. Slow steaming delays the receipt of a tanker's next cargo.

There were two types of engines in common use during the period under consideration, stearn turbines and diesels. Steam turbines are more expensive, but have lower maintenance costs. Steam turbines had about a $30 \%$ thermal efficiency while the older diesels had a thermal efficiency of about $40 \%$. By the end of the period under consideration the thermal efficiency of diesels had risen to about $53 \%$. Since diesels consume less energy, they can travel further without refueling. Since steam turbines were less energy efficient it is not surprising that they gradually dropped 
from use. It should be noted that diesels are easy to slow steam, while steam turbines require major adjustments to do so. There were also some ships that had the main engine converted from steam to diesel power. This conversion is expensive.

There are a number of measures used in various ships in order to save energy. Electricity is generated by a separate diesel generator. By using power from the main engine to generate power while at sea, one can save on maintenance of the auxiliary engine. This also allows one to make use of the lower grade (and cheaper) fuel used by the main engine. The main drawback to this sort of power take-off is the capital cost involved in making the switch.

On older ships with less thermally efficient engines it has proved practical to convert the heat from the diesel exhaust into steam. In some cases enough electricity was thereby produced that it supplied all the sea going electricity needs of the ship.

Ship fuel derives from crude oil. The main engine uses mostly heavy residual fuel. The generators use distillates or blended fuel. Lubricants are also important to keep things running smoothly. Unlike oil products used in cars and airplanes, ships use low grade oil often containing impurities. In order to use even lower grade fuels some ships have added heaters in order to be able to blend the high viscosity fuel together with the distillate. Again in this case the economic trade-off is that more capital and maintenance is required to effect this shift. Relative prices will determine whether this makes sense for any particular ship.

The main component of a ship is steel. The hull is painted in order to reduce fouling by green slime, weeds and barnacles. Many paints are now designed to gradually release poison to reduce the fouling. Painting is also important to reduce corrosion and frictional resistance to the water. 
The use of relatively expensive self-polishing paints, such as those that use tributylin copolymer as a binder, helps to reduce energy demands, and has become more common recently.

Three additional sources of energy savings are also worth mentioning. There were significant improvements in propeller design. Ship board energy audits have saved literally thousands of dollars a year in some cases through reduced use of radar, lights and ventilation fans for example. Finally the amount of ballast used can be reduced. This saves energy, but increases risk if seas are heavy. The net effect of all these changes has been that a VLCC from the mid 1970s would typically travel about 5.4 miles per tonne of fuel. Ten years later a modern VLCC would travel about 7.7 miles per tonne. Not only has there been efforts to economize on energy. The typical crew size has also been changing. It has been shrinking. Over a ten or fifteen year period a typical crew has shrunk from 40 to 30 members. 


\section{References}

Berndt, E. R. (1991) The Practice of Econometrics: Classic and Contemporary. Addison-Wesley Publishing, Reading Mass..

Branch, A. E. (1988) Economics of Shipping Practice and Management, Second Edition. Chapman and Hall, London.

Drewry's Shipping Statistics and Economics, various, Drewry Shipping Consultants, London.

Eckstein, Z. and K. I. Wolpin (1989) "The Specification and Estimation of Dynamic Stochastic Discrete Choice Models: A Survey", Journal of Human Resources, 23, 4, 562-598.

Feldstein, M. S. and M. Rothschild (1974) "Towards an Economic Theory of Replacement Investment", Econometrica, 42, 3, 393-423.

Hall, R. E. (1988) "The Relationship between Price and Marginal Cost in U.S. Industry", Journal of Political Economy, 96, 5, 921-947.

Hall, R. E. (1989) "Invariance Properties of Solow's Productivity Residual", NBER Working Paper \#3034.

Hughes, C. N. (1987) Ship Performance: Some Technical and Commercial Aspects. Lloyd's of London Press Ltd., Colchester, Great Britain.

Hulten, C. R. (1990) "The Measurement of Capital", in Berndt, E. R. and J. Triplett, (eds.) Fifly Years of Economic Measurement, Chicago: University of Chicago Press.

Hulten, C. R., J. W. Robertson, and F. C. Wykoff (1989) "Energy, Obsolescence, and the Productivity Slowdown", in D. W. Jorgenson and R. Landau (eds.), Technology and Capital Formation, MIT Press, Cambridge Mass.

Hulten, C. R. and F. C. Wykoff (1981) "The Estimation of Economic Depreciation Using Vintage Asset Prices: An Application of the Box-Cox Power Transformation", Journal of Econometrics, $15,3,367-396$. 
ISL Shipping Statistics, various, Institute of Shipping Economics and Logistics, Bremen.

Jorgenson, D. W. (1989) "Capital as a Factor of Production", in D. W. Jorgenson and R. Landau, (eds.) Technology and Capital Formation, MIT Press, Cambridge Mass.

Lloyd's List, various, Westmead, Hants.

Lloyd's Register of Shipping, various, Wyman and Sons, London.

McFadden, D. (1981) "Econometric Models of Probabilistic Choice", in C. Manski and D. McFadden, (eds.), Structural Analysis of Discrete Data, MIT Press, Cambridge, Mass.

Ohta, M. and Z. Griliches (1986) "Automobile Prices and Quality: Did the Gasoline Price Increases Change Consumer Tastes in the US?", Journal of Business and Economic Statistics, 40, 2, 187198.

Pakes, A. (1991) "Dynamic Structural Models: Problems and Prospects. Mixed Continuous Discrete Controls and Market Interactions", Cowles Foundation Discussion Paper No. 984.

Pakes, A. and Z. Griliches (1984) "Estimating Distributed Lags in Short Panels with an Application to the Specification of Depreciation Patterns and Capital Stock Constructs", Review of Economic Studies, 51, 243-262.

Pindyck, R. S. (1991) "Irreversibility, Uncertainty, and Investment", Journal of Economic Literature, 29, 3, 1110-1148.

Rust, J. (1988) "Maximum Likelihood Estimation of Discrete Control Processes", SIAM Journal of Control and Optimization, 26, 5, $1006-1024$.

Rust, J. (1992) "Do People Behave According to Bellman's Principle of Optimality?", Hoover Institution, Working Papers in Economics E-92-10. 
Ruud, P. (1982) "Sufficient Conditions for the Consistency of Maximum Likelihood Estimation Despite Misspecification of Distribution in Multinomial Discrete Choice", Econometrica, 51, 225-228.

Stokey, N. L. and R. E. Lucas, Jr. (1989) Recursive Methods in Economic Dynamics. Harvard University Press, Cambridge Mass.

Stopford, M. (1988) Maritime Economics. Allen \& Unwin Inc., Winchester Mass.

United States Department of the Treasury, Bureau of Internal Revenue (1942) "Bulletin "F": Income Tax, Depreciation, and Obsolescence, Estimated Useful Lives and Depreciation Rates", Government Printing Office, Washington, DC.

Yatchew, A. and Z. Griliches (1985) "Specification Error in Probit Models", Review of Economics and Statistics, 66, 134-139.

Winfrey, R. (1935) "Statistical Analyses of Industrial Property Retirements", Iowa Engineering Experiment Station, Bulletin no. 125 . 
Table 1

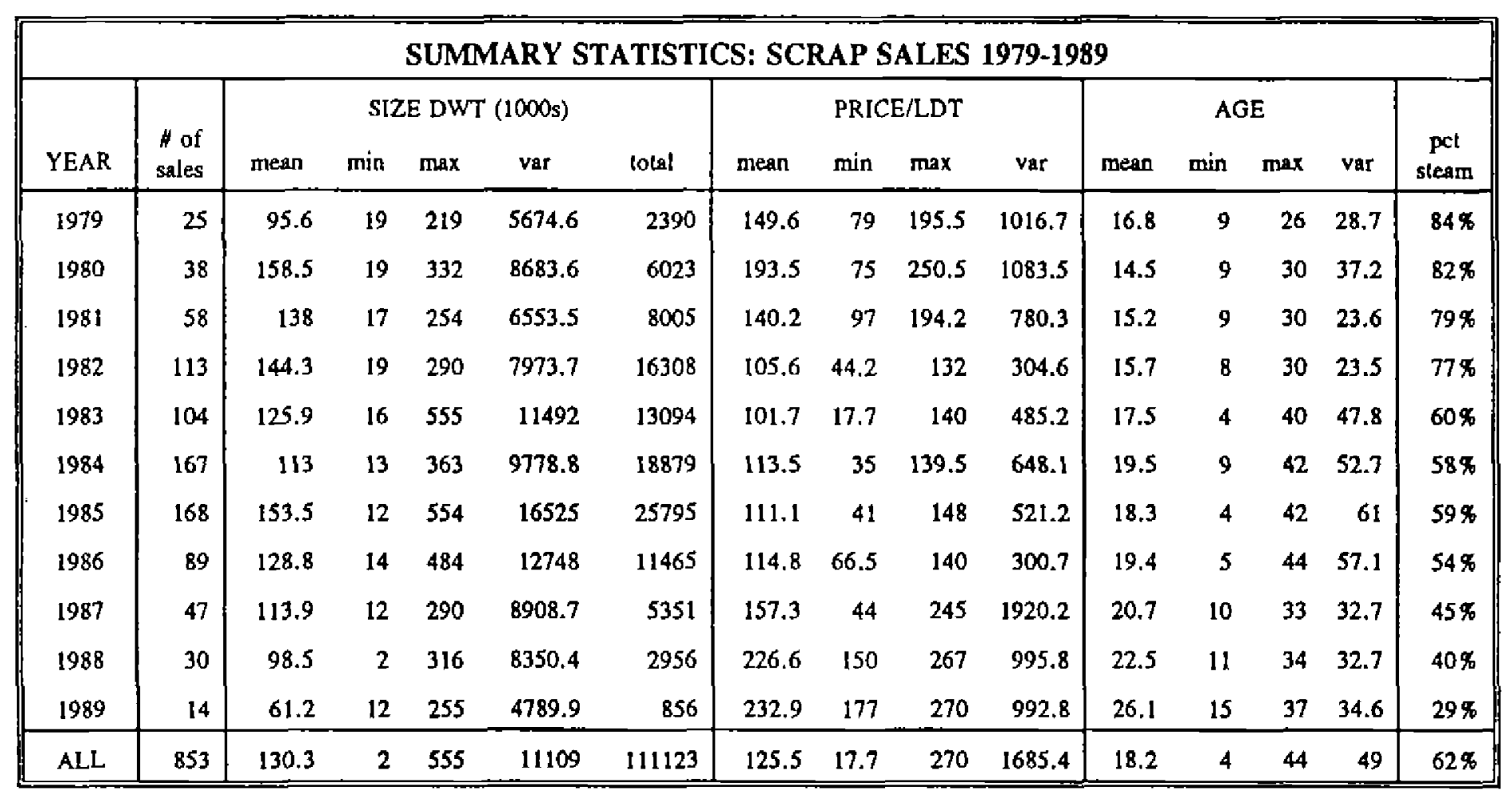

$A G E$ is the number of years since the ship was built.

SIZE is thousands of deadweight tonnes.

PRICE/LDT is cutrent US dollars per lightweight displacement tonne.

PCT STEAM is the fraction of sales in that year which were steam-powered tankers

Source: Sales and prices from Drewny's and Lloyd's List, various volumes AGE, DWT from Drewry's and Lloyd's Register, various volumes 
Table I

\begin{tabular}{|c|c|c|c|c|c|c|c|c|c|c|c|c|c|c|c|}
\hline \multicolumn{16}{|c|}{ SUMMARY STATISTICS: SECOND HAND MARKET TRANSACTIONS 1979-1989 } \\
\hline \multirow[b]{2}{*}{ YEAR } & \multirow{2}{*}{$\begin{array}{l}\text { \# of } \\
\text { sales }\end{array}$} & \multicolumn{5}{|c|}{ SIZE DWT (1000s) } & \multicolumn{4}{|c|}{ PRICE/DWT } & \multicolumn{4}{|c|}{ AGE } & \multirow{2}{*}{$\begin{array}{c}\text { pct } \\
\text { steam }\end{array}$} \\
\hline & & mesn & min & $\max$ & var & total & mean & $\min$ & $\max$ & var & mean & min & $\max$ & Var & \\
\hline 1979 & 150 & 108.8 & 14 & 424 & 7437.7 & 16325 & 145.6 & 7.8 & 694.4 & 26767 & 10.1 & 1 & 26 & 40.3 & $39 \%$ \\
\hline 1980 & 130 & 104 & 14 & 380 & 6717.4 & 13515 & 161.8 & 26 & 664 & 24723 & 10.7 & 2 & 29 & 35.5 & $22 \%$ \\
\hline 1981 & 139 & 105.7 & 12 & 417 & 8480.5 & 14692 & 96.6 & 9 & 682 & 18271 & 13 & 3 & 25 & 26.8 & $27 \%$ \\
\hline 1982 & 111 & 120.4 & 12 & 491 & 11118 & 13370 & 78.7 & 10 & 615 & I 1522 & 11.5 & 1 & 22 & 24.1 & $34 \%$ \\
\hline 1983 & 75 & 108.3 & 16 & 332 & 8606.2 & 8119 & 93.6 & 8 & 592 & 14283 & 11.3 & 1 & 23 & 25.4 & $27 \%$ \\
\hline 1984 & 159 & 118 & 11 & 491 & 12813 & 18760 & 106 & 14 & 730 & 19020 & 11.5 & 0 & 24 & 32.2 & $28 \%$ \\
\hline 1985 & $16 \mathrm{I}$ & I 23.4 & 18 & 555 & 11401 & 19865 & 74.4 & 11 & 325 & 4092.2 & 10.7 & 1 & 43 & 24.7 & $21 \%$ \\
\hline 1986 & 199 & 134.2 & 14 & 433 & 13472 & 26697 & 91.8 & 13 & 410 & 6239 & 11.2 & 0 & 27 & 22.3 & $27 \%$ \\
\hline 1987 & 171 & 118.5 & 10 & 357 & 9266.4 & 20266 & 136.2 & 23 & 651 & 15240 & 11.9 & 1 & 27 & 21.7 & $24 \%$ \\
\hline 1988 & 220 & 103.1 & 10 & 565 & 7941.3 & 22683 & 177.5 & 19 & 659.7 & 15851 & 11.9 & 0 & 23 & 18 & $19 \%$ \\
\hline 1989 & 271 & 88.2 & 11 & 565 & 6353.1 & 23915 & 316.8 & 34 & 1300 & 53575 & 11.2 & 0 & 30 & 29.2 & $11 \%$ \\
\hline ALL & 1786 & 111 & 10 & 565 & 9453.8 & 198206 & 149.7 & 7.8 & 1300 & 27065 & 11.4 & 0 & 43 & 27.2 & $24 \%$ \\
\hline
\end{tabular}

AGE is the number of years since the ship was built.

SIZE is thousands of deadweight tonnes.

PRICE/DWT is current US dollars per deadweight tonne.

PCT STEAM is the fraction of sales in that year which were steam-powered tankers

Source: Sales and prices from Drewry's and Lloyd's List, various volumes Age, dwt from Drewry's and Lloyd's Regisler, various volumes 
Table III

OLS Regression Results: Price Equations for the Second Hand Market 1

\begin{tabular}{|c|c|c|c|c|c|c|c|c|c|c|}
\hline & \multicolumn{2}{|c|}{ Equation Ia } & \multicolumn{2}{|c|}{ Equation $1 \mathrm{~b}$} & \multicolumn{2}{|c|}{ Equation 2a } & \multicolumn{2}{|c|}{ Equation $2 b$} & \multicolumn{2}{|c|}{ Equation $2 c$} \\
\hline & Est & $S E$ & Est & SE & Est & $S E$ & Est & $\mathrm{SE}$ & Est & SE \\
\hline INTERCEPT & 6.611 & 0.0494 & 6.203 & 0.0792 & 7.042 & 0.0564 & 6.620 & 0.0773 & 6.529 & 0.0958 \\
\hline$A G E$ & -0.024 & 0.0007 & -0.025 & 0.0005 & -0.027 & 0.0008 & -0.026 & 0.0005 & -0.026 & 0.0005 \\
\hline AGE * STEAM & & & & & 0.029 & 0.0022 & 0.016 & 0.0015 & 0.012 & 0.0019 \\
\hline DWT & -0.120 & 0.0052 & -0.123 & 0.0033 & -0.194 & 0,0092 & -0.189 & 0.0059 & -0.188 & 0.0057 \\
\hline DWT * STEAM & & & & & 0.195 & 0.0138 & 0.147 & 0.0090 & 0.136 & 0.0099 \\
\hline $\mathrm{DWT}^{2}$ & 0.002 & 0.0001 & 0.002 & 0.0001 & 0.005 & 0.0004 & 0.005 & 0.0003 & 0.005 & 0.0002 \\
\hline DWT $^{2}$ * STEAM & & & & & -0.005 & 0.0004 & -0.004 & 0.0003 & -0.004 & 0.0003 \\
\hline STEAM & -0.290 & 0.0535 & -0.136 & 0.0351 & -3.489 & 0.2112 & -2.154 & 0.1448 & -1.708 & 0.2084 \\
\hline $\begin{array}{l}\text { QUARTER } \\
\text { DUMMIES }\end{array}$ & No & & YES & & NO & & YES & & DIESEL & STEAM $^{\dagger}$ \\
\hline RMSE & 0.639 & & 0.404 & & 0.595 & & 0.373 & & 0.362 & \\
\hline R-squared & 0.617 & & 0.851 & & 0.668 & & 0.873 & & 0.883 & \\
\hline Adj R-sq & 0.617 & & 0.847 & & 0.667 & & 0.869 & & 0.877 & \\
\hline
\end{tabular}

Notes: 1786 observations on sales of oil tankers for further trading, from Drewry's monthly reports January 1979 to December 1990.

Dependent variable is natural logarithm of price per deadweight ton. AGE is age of the ship, in quarters, based on the year it was built, as listed in Lloyd's Register. DWT is size measured in 10,000 deadweight tons. STEAM is a dummy variable equal to one when the ship is steam powered, zero otherwise.

In equation $2 \mathrm{c}$ steam and diesel tankers each have their own set of time dummies. 
Table IV

OLS Regression Results: Price Equations for the Second Hand Market II

\begin{tabular}{|c|c|c|c|c|c|c|c|c|}
\hline & \multicolumn{2}{|c|}{ Equation $\mathrm{lb}$} & \multicolumn{2}{|c|}{ Equation lc } & \multicolumn{2}{|c|}{ Equation $2 b$} & \multicolumn{2}{|c|}{ Equation $2 d$} \\
\hline & Est & SE & Est & SE & Est & SE & Est & SE \\
\hline INTERCEPT & 6.203 & 0.0792 & 7.492 & 0.0610 & 6.620 & 0.0773 & 7.719 & 0.0657 \\
\hline AGE & -0.025 & 0.0005 & -0.025 & 0.0007 & -0.026 & 0.0005 & -0.027 & 0.0007 \\
\hline AGE * STEAM & & & & & 0.016 & 0.0015 & 0.020 & 0.0025 \\
\hline DWT & -0.123 & 0.0033 & -0.123 & 0.0046 & -0.189 & 0.0059 & -0.187 & 0.0085 \\
\hline DWT " STEAM & & & & & 0.147 & 0.0090 & 0.156 & 0.0140 \\
\hline $\mathrm{DWT}^{3}$ & 0.002 & 0.0001 & 0.002 & 0.0001 & 0.005 & 0.0003 & 0.005 & 0.0004 \\
\hline $\mathrm{DWT}^{2} *$ STEAM & & & & & -0.004 & 0.0003 & -0.004 & 0.0004 \\
\hline STEAM & -0.136 & 0.0351 & -0.128 & 0.0485 & -2.154 & 0.1448 & -2.619 & 0.3335 \\
\hline BUNKER FUEL PRICE & & & -0.004 & 0.0002 & & & -0.004 & 0.0002 \\
\hline $\begin{array}{l}\text { (BUNKER FUEL PRICE) } \\
\text { " STEAM }\end{array}$ & & & & & & & 0.0006 & 0.0005 \\
\hline $\begin{array}{l}\text { QUARTER } \\
\text { DUMMIES } \\
\end{array}$ & YE & & $\mathbf{N}$ & & & & & \\
\hline RMSE & 0.404 & & 0.572 & & 0.373 & & 0.549 & \\
\hline R-squared & 0.851 & & 0.693 & & 0.873 & & 0.718 & \\
\hline Adj R-sq & 0.847 & & 0.693 & & 0.869 & & 0.717 & \\
\hline
\end{tabular}

Notes: 1786 observations on sales of oil tankers for further trading, from Drewry's monthly reports January 1979 to December 1990.

Dependent variable is natural logarithm of price per deadweight ton. AGE is age of the ship, in quarters, based on the year it was built, as listed in Lloyd's Register. DWT is size measured in 10,000 deadweight tons. STEAM is a dummy variable equal to one when the ship is steam powered, zero otherwise. BUNKER FUEL PRICE is the quarterly average price of Marine Diesel Oil at Rotterdam, in US\$/lonne. 
Table V

OLS Regression Results: Price Equations for the Scrap Market

\begin{tabular}{|c|c|c|c|c|c|c|c|c|c|c|}
\hline & \multicolumn{2}{|c|}{ Equation $3 a$} & \multicolumn{2}{|c|}{ Equation 3b } & \multicolumn{2}{|c|}{ Equation 4a } & \multicolumn{2}{|c|}{ Equation $4 b$} & \multicolumn{2}{|c|}{ Equation $4 \mathrm{c}$} \\
\hline & Est & $S E$ & Est & $S E$ & Est & $S E$ & Est & $\mathrm{SE}$ & Est & SE \\
\hline INTERCEP & 4.782 & 0.0790 & 5.050 & 0.0806 & 4.616 & 0.1174 & 4.971 & 0.1001 & 4.807 & 0.2091 \\
\hline AGE & $-0.00 \mathrm{I}$ & 0.0007 & -0.003 & 0.0005 & 0.00003 & 0.0009 & -0.003 & 0.0006 & -0.003 & 0.0006 \\
\hline AGE * STEAM & & & & & -0.002 & 0.0014 & 0.0004 & 0.0009 & 0.000 & 0.0010 \\
\hline DWT & 0.011 & 0.0044 & 0.003 & 0.0029 & 0.027 & 0.0112 & 0.021 & 0.0071 & 0.022 & 0.0072 \\
\hline DWT * STEAM & & & & & -0.023 & 0.0125 & -0.018 & 0.0080 & -0.019 & 0.0082 \\
\hline $\mathrm{DWT}^{2}$ & -0.0003 & 0.0001 & -0.0001 & 0.0001 & -0.001 & 0.0004 & -0.001 & 0.0003 & -0.001 & 0.0003 \\
\hline DWT $^{2}+$ STEAM & & & & & 0.0004 & 0.0004 & 0.001 & 0.0003 & 0.001 & 0.0003 \\
\hline STEAM & 0.011 & 0.0260 & 0.022 & 0.0172 & 0.307 & 0.1697 & 0.058 & 0.1123 & 0.235 & 0.2338 \\
\hline $\begin{array}{l}\text { QUARTER } \\
\text { DUMMIES }\end{array}$ & No & & YES & & NO & & YES & & DIESEL + & $\operatorname{TEAM}^{\dagger}$ \\
\hline RMSE & 0.315 & & 0.197 & & 0.315 & & 0.197 & & 0.195 & \\
\hline R-squared & 0.035 & & 0.641 & & 0.041 & & 0.646 & & 0.668 & \\
\hline Adj R-sq & 0.030 & & 0.620 & & 0.033 & & 0.624 & & 0.628 & \\
\hline
\end{tabular}

Notes: 853 sales for scrap reported in Drewry's and Lloyd's List, various volumes 1979-1989.

Dependent variable is natural logarithm of price per deadweight ton. AGE is age of the ship, in quarters, based on the year it was built, as listed in Lloyd's Register. DWT is size measured in 10,000 deadweight tons. STEAM is a dummy variable equal to one when the ship is steam powered, zero otherwise.

†In equation $4 c$ steam and diesel tankers each have their own set of time dummies. 
Table VI

Logit Estimates of Scrapping

\begin{tabular}{|c|c|c|c|c|c|c|c|c|}
\hline & \multicolumn{2}{|c|}{ Equation 5a } & \multicolumn{2}{|c|}{ Equation $S b$} & \multicolumn{2}{|c|}{ Equation $S e$} & \multicolumn{2}{|c|}{ Equation Sd } \\
\hline & Est & SE & Est & SE & Est & $\mathrm{SE}$ & Est & SE \\
\hline INTERCEPT & -6.317 & 0.217 & -2.729 & 0.392 & -3.364 & 0.353 & -1.680 & 0.539 \\
\hline AGE & 0.029 & 0.002 & 0.008 & 0.003 & 0.013 & 0.002 & -0.0006 & 0.0035 \\
\hline AGE * STEAM & & & " & & & & 0.029 & 0.004 \\
\hline DWT & 0.158 & 0.016 & 0.044 & 0.019 & 0.080 & 0.017 & 0.009 & 0.049 \\
\hline DWT * STEAM & & & & & & & 0.134 & 0.052 \\
\hline $\mathrm{DWT}^{2}$ & -0.003 & 0.0004 & -0.001 & 0.0004 & -0.0017 & 0.0004 & -0.0007 & 0,002 \\
\hline DWT ${ }^{2} *$ STEAM & & & & & & & -0.002 & 0,002 \\
\hline STEAM & 0.170 & 0.080 & -0.025 & 0.081 & -0.037 & $0.08 \mathrm{I}$ & -3.286 & 0.546 \\
\hline P-HAT1 & & & -0.029 & 0.003 & & & & \\
\hline P-HAT2 & & & & & -0.029 & 0.003 & -0.032 & 0.003 \\
\hline $\begin{array}{l}\text { Chi-sq goodness } \\
\text { of fit (df) }\end{array}$ & & $0.27(4)$ & & $413.2(5)$ & & $402.4(5)$ & & $460.5(8)$ \\
\hline $\begin{array}{l}\text { log-likelihood } \\
\text { function }\end{array}$ & & -3654.7 & & -3593.2 & & .3598 .6 & & -3569.6 \\
\hline
\end{tabular}

Noles: 19614 observations, based on transactions reported in Drewry's and Lloyd's List, various volumes, $1979-1989$

Dependent variable is equal to 1 if the ship is scrapped in that quarter, 0 otherwise. AGE is age of the ship, in quarters, based on the year it was built, as listed in Lloyd's Register. DWT is size measured in 10,000 deadweight tons. STEAM is a dumny variable equal to one when the ship is steam powered, zero otherwise. P-HATl is the predicted price/dwi for which the ship could be sold for further trading, based on the parameters estimated in Equation $1 \mathrm{~b}$ above. P-HAT2 is the predicted price/dwt based on Equation $2 \mathrm{~b}$ above. 